\title{
Will Bilingualism Be Valid among the Younger Generations in Kazakhstan?
}

\author{
Ziash Suleimenova and Altynay Tursun
}

\begin{abstract}
Large parts of the titular population in Kazakhstan have a better command of Russian than of their own 'mother tongue', or they could not speak their mother tongue at all.Some Kazakhs prefer to use the Russian language in daily conversation, and do so without any pangs of guilty conscience. Some Russian-speaking Kazakhs had started sending their youngsters to Kazakh-medium schools in the hopes that the school could provide them with skills in Kazakh that they themselves lack. The study focuses on these issues of the language policy in Kazakhstan in general, and bilingualism in particular. There are voices that additional languages present a threat to the national language. Besides, teaching of Russian and English threaten the development of national identity. The problem under investigation is whether younger generations will keep the retention as to the bilingualism. Or else the trilingual policy offered by the President Nazarbayev will make the country a multilingual community.
\end{abstract}

Index Terms - Bilingualism, language policy, multilingualism, mother tongue.

\section{INTRODUCTION}

Bilingualism has become an integral and necessary part of language policy in Kazakhstan. According to the law the status of the Kazakh language is determined as official. But nevertheless there is a complicated language situation in Kazakhstan: the Kazakh language is not functioning in full, the youth takes a fancy to foreign languages and actively learns them (especially English); the 'Pigeon' language is developing ('pigeon' means mixed, for example, Russian Kazakh or Kazakh - Russian).

\section{AN OVERVIEW OF BILINGUALISM IN KAZAKHSTAN}

The history of the development of Kazakh-Russian bilingualism can be divided into several phases [1]. They are marked by the gradual loss of social domains and prestige of Kazakh, as well as an increasing support of the Russian language by the government, from 1917 to 1923 . At that time, Kazakh had been written in there formed Arabic script; there were several Kazakh newspapers and magazines. At the time after the October Revolution, written Kazakh was a mixture of Kazakh and other Turkic languages. At that time, Russian was not widely known among Kazakhs, since the number of the

Russians in Kazakhstan was not very high [1].

In the years from 1924 to 1927 , there was a change in the

Manuscript received August 9, 2014; revised October 10, 2014.

The authors are with the KIMEP University, Almaty, Kazakhstan (e-mail: ziash@kimep.kz, atursun@kimep.kz).
Soviet language policy, which led to the addition of new social functions for Kazakh. In 1929, the Arabic alphabet was replaced by the Latin script. It was in 1940 that the Cyrillic alphabet replaced the Latin alphabet. The ethnic composition of the population changed dramatically, for several reasons such as, for example, the mass deportation of the Volga Germans, Chechen peoples, Koreans and other ethnicities before the Second World War, as well as the evacuation of many people from the European part of the Soviet Union to Kazakhstan during that war.

From 1954 to 1955, another change in the ethnical structure in Kazakhstan took place, as a consequence of the agricultural development of the northern Kazakh steppe in the region of the current capital of Kazakhstan. From that point on, the Russian-speaking population increased considerably. However, since the late 1980s nearly 2 million Russian-speaking people [2], as well as 1.5 million Germans, left Kazakhstan. In the 1990s, the Diaspora Kazakhs immigrated into Kazakhstan from Mongolia and China (so-called oralmans-'people who returned to their native land').

\section{RESEARCH AIMS AND OBJECTIVES}

The issue of bilingualism in Kazakhstan seems to be a fruitful research direction to focus on. With this topic under investigation one might find opportunities to renegotiate ethnic, linguistic, and national identities of participants of the given research, the status of minority languages not limited to Russian, language rights of both parties, and others.

There are voices that additional languages present a threat to the national language. In Kazakhstan some members of national elites argue that English and Russian are a threat to the purity and development of the titular language [3], [4]. Besides, in their opinions, teaching of Russian and English threaten the development of national identity [5].

Large parts of the titular population in Kazakhstan have a better command of Russian than of their own 'mother tongue', or they could not speak their mother tongue at all. Some Kazakhs prefer to use the Russian language in daily conversation, and do so without any pangs of guilty conscience. Some Russian-speaking Kazakhs had started sending their youngsters to Kazakh-medium schools in the hopes that the school could provide them with skills in Kazakh that they themselves lack.

Many research studies cite the cognitive-linguistic benefits of being a fluent bilingual speaker. In addition, as our world shrinks and business becomes increasingly international, children who are fluent bilingual speakers are potentially a tremendously valuable resource for our economy. 
The major purpose of the given research was to investigate interaction among bilingual Kazakhs in everyday situations. In other words, what the factors or sources are that make speaking two languages preferable. People, who are currently monolingual speakers of English, find that it would be highly advantageous to their professional lives if they spoke a second language.

The second most important aim of this study was to give attention to the phenomenon of bilingualism in Kazakhstan. It will also inform the teachers about the phenomenon, as a learner, as well as a practitioner in language teaching. In addition, integrating the findings of this research on bilingualism - regarding its nature, sources, effects and treatment - with the existing literature is also an underlying consideration of the study. This was an attempt to understand more fully the role that bilingualism may play in our lives.

This study utilized the qualitative research tradition, namely the semi-structured interview. The present study aimed to contribute to our understanding of bilingualism, in general, and bilingualism in Kazakhstani environment, in particular. The present study was the first attempt to fill this gap and to reveal more about the bilingualism of Kazakh students group, having considered how it affected speaking, overall classroom performance, and its usage in everyday life of participants.

\section{PARTICIPANTS OF THE RESEARCH}

Bilingual speakers under investigation were 11 bilingual Kazakhs (5 males, 6 females), students of a local university who acquired and maintained at least one language during childhood, the so-called first language (L1). The first language (sometimes also referred to as the mother tongue) is acquired without formal education, by mechanisms heavily disputed. The age of the participants ranged between 18-21 years at the time of recording. People acquiring two languages in this way are called simultaneous bilinguals. They are participants of the given study. Prior to the interviews, the author was unfamiliar with the participants. Most of them could be qualified as balanced bilinguals with a high competence in Kazakh and Russian.

\section{Methodology}

This study is based on data that were collected by the researchers in Almaty, Kazakhstan. The first part consists of a semi-structured interview; the second part contains field notes. Both interview and field notes were made in the classroom or partly during the lunch break at the participants' study place. The interview questions covered childhood and travel experiences, the study situation, as well as family affairs. Only two participants spoke Kazakh as dominant. In the conversation among bilingual Kazakhs, code-mixing is the unmarked choice; the alternative use of two languages is a common discourse mode among urban Kazakhs.

The problem under investigation was whether younger generations would keep the retention as to the bilingualism. The following research was deliberately conducted in order to analyze a problem related to the existing bilingualism in
Kazakhstan. This linguistic situation is considered as one of the debatable questions in Kazakhstan.

The study set out to answer the following research questions:

1) What are the advantages and disadvantages of being bilingual?

2) What are the factors and sources that make speaking two languages preferable?

3) How will the younger generation retain bilingualism?

The first research question dealt with the ways of identifying benefits and drawbacks of being bilingual. The results of the given research revealed that being bilingual for the participants helped their minds expand linguistically in a way that would give them an educational advantage (personal communication, January 15, 2013). Speaking two languages allows stretching understanding of people beyond their dominant culture (personal communication, January 15, 2013). Being able to step into another culture through its language is like being able to live a second life (personal communication, January 15, 2013).

Although some bilinguals do not have a lot of exposure to the culture of their second language, the language itself conveys much of the culture of the people who speak that language. Further, even if bilinguals are not living with native speakers of their second language in their house or community, they are still likely to be exposed to traditions, original songs and stories from that culture.

Bilinguals have some experience seeing how different cultures cause different people to interpret completely differently the exact same circumstance. They understand at an early age that there is more than one way to label or discuss something. They understand that different labels for the same object or idea in different languages can have different connotations. They are more likely to see the creative possibilities of language and explore that we live in an ever smaller world where languages are the only barrier, distances are no longer. So there is a clear economic advantage of being bilingual.

Another advantage is flexible and divergent thinking skills. Bilinguals know from the start that there could be more than one word to one concept. Bilinguals seem to think more freely, more elaborately and more creatively. One's self-identity will be affected as well. It increases the self-esteem and the self-confidence. Their self esteem is boosted making them more successful in other parts of their life. They become motivated to learn new things.

Communication advantages are apparent with bilinguals communicating with extended family, community, and international links. Bilinguals may also be bridge builders between different languages. Bilingualism helps to learn a third language.

Due to expanding technology, our world has become a much smaller community. We are now encountering more people with diverse backgrounds and languages. Many people are now speaking languages other than their native tongue. It used to be common to speak two languages but now speaking a third language is becoming popular.

Those who are bilingual and are learning a third language have been found to have a better understanding of how the third language works because they can draw distinctions 
between the other two languages. They are able to identify the similarities regarding grammar, spelling, vocabulary, as well as identify similar words, phrases and sentence structures. They are also able to quickly and easily understand the various language rules.

Because language is the principal communication tool, the more languages one learns the more valuable they become in terms of their career. People fluent in two languages have certain cognitive advantages compared to those who speak only one. They are better at problem solving, demonstrate greater creativity, and express more tolerant attitudes toward others, for instance.

There are a lot of advantages and good reasons to tackle multilingualism or bilingualism. But to be complete, we should have a look into disadvantages:

When applying for a job preference will be given to the people who have essential skills and knowledge in both Kazakh and Russian, as well as among required terms is knowledge of the $3 \mathrm{~d}$ language, namely English. If one does not meet this requirement he or she will not be a good candidate and lose the position. Frequent code-switching while being bilingual might be an obstacle for communication.

Another potential disadvantage is the added academic load. Most often bilinguals go to a monolingual school. Some have the advantage to go to a bilingual school, but the majority of children, even though they grow up bilingual or multilingual, they still go to a monolingual school. This means that if you also want to read and write in the second or third or fourth language, you will have to find a way to add that to your curriculum. So that means extra hours, extra work in the afternoons after the normal regular school. And that has to be organized and that is an effort that you have to put in and yourself.

Although much evidence suggests that bilinguals are not intellectually disadvantaged from their monolingual peers, it is possible for bilingual children to not develop adequately enough either of the two languages they are learning to be able to be an effective student at school in either language. This is most likely to happen in a scenario where the person doesn't have enough exposure to their preferred language (probably the dominant language of the community) since his or her parents do not use and may not know that language, and the child resists speaking the language that is spoken at home. It is avoidable.

You may not have a true sense of identity and feel you don't really belong to any one culture. There may be friction in your family should you reject one culture for the other, or just be more interested in the culture of where you live. Parents keep telling to their kids: Don't speak Russian at home, let us all practice our native language (personal communication, January 15, 2013). This is where internal family conflicts between parents and their kids arise. You might mix up your languages when you speak or think. Bilingual people usually are either better at one language, or worse at the other, or they might not be able to fully grasp both.

Thus, in the process of becoming bilingual, native aptitude, age and intelligence are less important than a supportive context of necessity. With the right social conditions, then, bilingualism becomes just as "natural" as monolingualism in others, and is a capacity available and accessible to anyone of normal or standard talents and abilities. This study utilized the qualitative research tradition; the semi-structured interview questions were designed to find out the major factors concerning bilingualism reported by participants.

\section{CONCLUSION}

One can only hope that in the future linguists and educators working in this area will play a more prominent part in the public arena, following an example of Bill Fierman [6], an expert on Central Asia, who regularly takes part in debates and gives interviews to the Kazakh press on the benefits of bilingualism and linguistic tolerance. Disagreement about which languages should be supported, when, how, and for what purpose is seen as a productive way to generate debates that in turn could lead to more extensive studies and we hope to the development of more democratic forms of minority integration and language policy-making, in which 'non-dominant ethno-linguistic groups can shape the language policies that affect them' [7].

Great Abai, a prominent Kazakh poet, once said that through Russian the Kazakhs would learn about the world culture and spiritual values. And it really was so. The Russian language and culture have spiritually enriched and educated the Kazakh people who are frankly thankful for this. And the language of Pushkin is used along with Kazakh in official record management and widely used in interethnic communication. Kazakhstan must become a highly educated country, said Nursultan Nazarbayev, which requires the knowledge of at least three languages: Kazakh (state language), Russian (for interethnic communication) and English (to integrate in the global economy). If trilingualism is now the goal of Kazakhstan and it is seen as useful to the population, the role and purpose behind bilingualism will become all the more present, prevalent, and important.

\section{ACKNOWLEDGMENT}

We would like to extend our special thanks to our colleagues from KIMEP University for all their help and support. We are extremely thankful to all the participants who provided us rich and detailed data for the study and lent breadth and value to the research findings.

\section{REFERENCES}

[1] B. Xasanov, Languages of the People of Kazakhstan and Their Interrelations, Alma-Ata: Nauka, 1976.

[2] E. D. Suleimenova, N. Z. Shaimerdenova, and D. X. Akanova, Dictionary of Sociolinguistic Terms, Almaty: Kazakh Universiteti, 2007.

[3] A. Baygozhina, "Language policy: Creative ideas are necessary," Baiterek, vol. 4, no. 25, 2007.

[4] J. Popjanevsky, Minorities and the State in the South Caucasus: Assessing the Protection of National Minorities in Georgia and Azerbaijan, 2006.

[5] Bulajeva and Hogan-Brun, "Language and education orientations in Lithuania: A cross-baltic perspective post-EU accession," Multilingualism in Post-Soviet Countries, Clevedon: Multilingual Matters, 2008

[6] W. Fierman, "Kazakh language and prospects for its role in Kazakh 'groupness'," Ab Hnperio, vol. 2, pp. 393-423, 2005.

[7] J. Toleffson, "Critical theory in language policy," An Introduction to Language Policy: Theory and Method, pp. 42-59, Madlen, MA: Blackwell, 2006. 
Ziash Suleimenova was born in the north of Kazakhstan in 1953. She got her bachelor's degree in the field of teaching English in the Univerity of Kostanay, Kazakhstan, in 1974.

She worked as an English instructor at the Industrial University teaching civil engineering, mining, and electrical students English for specific purposes. She had a professional development training at the Moscow Mining University in 1991. She got her master's in TESOL at the KIMEP University. She has been a lecturer at the KIMEP University for about 13 years. She published several articles.

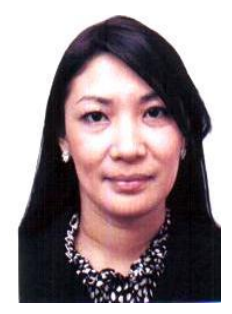

Altynay Tursun was born in Rudny, Kazakhstan, in 1977. She got her bachelor's degree in the field of teaching English in the University of Kostanay, Kazakhstan,in 1998. She got her master's in business administration at the KIMEP University in 2008. She has been a lecturer at the KIMEP University for about 10 years. She has been teaching academic English courses. Her publications include: Ways of Providing Effective Feedback, Kaz TEA Conference on Language Teaching and Learning: Challenges and Opportunities, Shymkent, Republic of Kazakhstan, MIRAS University, 26-27 April 2014, etc. 